\title{
Expression of PTEN and $K A I 1$ tumor suppressor genes in pancreatic carcinoma and its association with different pathological factors
}

\author{
WEIDONG HUANG, JIE YANG, JUN REN and JIANJUN TANG \\ Department of General Surgery, Xiangyang Hospital Affiliated to Hubei University \\ of Medicine, Xiangyang, Hubei 441000, P.R. China
}

Received October 13, 2015; Accepted November 17, 2015

DOI: $10.3892 / \mathrm{ol} .2015 .3932$

\begin{abstract}
Pancreatic carcinoma is a common cancer type with a poor prognosis. The aim of the present study was to examine the expression of tumor suppressor genes phosphatase and tensin homolog deleted in chromosome 10 (PTEN) and KAII in pancreatic carcinoma and its association with clinical pathological factors. A total of 50 hospitalized cases of pancreatic cancer including 28 males and 22 females aged 31-82 years were included in the present study. Ten cases of normal pancreatic tissue were obtained from cadavers and served as the controls. The pancreatic specimens were embedded in paraffin blocks and slides were prepared for immunohistochemical analysis to determine the expression of PTEN and KAI1 in normal pancreatic tissue and pancreatic carcinoma samples. The positive expression rate of PTEN in the normal pancreatic tissue was higher than that in pancreatic carcinoma $(\mathrm{P}<0.05)$, while the positive expression rate of KAI1 in the normal pancreatic tissue was lower than that in pancreatic carcinoma $(\mathrm{P}<0.05)$. Pathological factors such as clinical stage of disease, histological grade and the presence or absence of lymphatic metastasis significantly affected the expression of PTEN and KAI1 $(\mathrm{P}<0.05)$. In conclusion, the positive expression of PTEN and KAI1 in pancreatic carcinoma is closely associated with the development of pancreatic carcinoma.
\end{abstract}

\section{Introduction}

Pancreatic carcinoma is a common type of cancer that is difficult to detect at the early stage owing to its latency and which has a poor prognosis. A possible reason for this is that phosphatase activity of tumor suppressor gene phosphatase and tensin homolog deleted in chromosome 10 (PTEN)

Correspondence to: Dr Jie Yang, Department of General Surgery, Xiangyang Hospital Affiliated to Hubei University of Medicine, 15 Jiefang Road, Xiangyang, Hubei 441000, P.R. China

E-mail: 1692710644@qq.com

Key words: pancreatic cancer, PTEN, KAI1, immunohistochemistry induces immoderate growth of genes $(1,2)$. The PTEN protein is widely expressed throughout the body and acts as a phosphatase for inhibition of the AKT signaling pathway. It is also one of the most commonly lost tumor suppressors in cancer. Mutations or deletions in PTEN inactivate its enzymatic activity leading to increased cell proliferation and reduced cell death (3).

Tumor metastasis suppressor gene, KAII, also known as $\mathrm{CD} 82$, has been reported to be associated with tumor metastasis and prognosis $(4,5)$. KAI1 is a member of the tetraspanin family based on its structural basis and as a metastatic suppressor gene based on functional grounds. Loss of KAI1 expression is associated with advanced stages of various human malignancies and results in invasive and metastatic behavior of tumor cells.

In the present study, we investigated the expression of PTEN and KAII tumor suppressor genes by determining their protein expression in pancreatic carcinoma through immunohistochemistry (IHC) to evaluate the clinical significance of the proteins in pancreatic cancer progression.

\section{Materials and methods}

Clinical samples. Pancreatic carcinoma samples were obtained from 50 hospitalized cases in the Xiangyang Hospital between 2008 and 2012. There were 28 males and 22 females aged $31-82$ years, with an average age of $53.8 \pm 11.4$ years. The cases were classified according to the TNM stage (6), with 8 cases in stage I, 15 cases in stage II, 24 cases in stage III and 3 cases in stage IV. For those cases, histological grade and case number, and presence or absence of lymphatic metastasis and case number are shown in Table I. In addition, 10 cases of normal pancreatic tissue samples obtained from the cadavers of 6 men and 4 women, aged 33-79 years, served as the control. The clinical specimens were embedded in paraffin blocks for analysis.

IHC for PTEN and KAIl. The pancreatic carcinoma samples were sectioned into $4 \mu \mathrm{m}$ slices prior to dewaxing and hydration. Subsequently, the sections were stained with diaminobenzidine and restained with hematoxylin. Phosphate-buffered saline was used as a negative control. The reaction was stopped 
Table I. PTEN expression in pancreatic carcinoma for three different pathological factors. ${ }^{\text {a }}$

A, Expression of PTEN by considering clinical stage (I-IV) of pancreatic cancer as pathological factor

\begin{tabular}{lcccc}
\hline Clinical stages & No. & Positive expression, no. & Positive expression rate, \% & P-value \\
\hline I, II & 23 & 14 & 60.87 & $<0.05$ \\
III, IV & 27 & 5 & 18.52 & $<0.05$ \\
\hline
\end{tabular}

B, Expression of PTEN by considering histological grade for cancerous pancreatic tissue as pathological factor

\begin{tabular}{lcccc}
\hline Histological grade & No. & Positive expression, no. & Positive expression rate, \% & P-value \\
\hline High differentiation & 12 & 8 & 66.67 & $<0.05$ \\
Intermediate differentiation & 22 & 8 & 36.37 & $<0.05$ \\
Poor differentiation & 16 & 3 & 18.75 & $<0.05$ \\
\hline
\end{tabular}

C, Expression of PTEN by considering lymphatic metastasis of pancreas as pathological factor

\begin{tabular}{lcccc}
\hline Lymphatic metastasis & No. & Positive expression, no. & Positive expression rate, \% & P-value \\
\hline No & 21 & 12 & 57.15 & $<0.05$ \\
Yes & 29 & 7 & 24.14 & $<0.05$ \\
\hline
\end{tabular}

${ }^{a} \mathrm{P}<0.05$ is considered as statistically significant. PTEN, phosphatase and tensin homolog deleted in chromosome 10.

Table II. KAI1 expression in pancreatic carcinoma for three different pathological factors. ${ }^{\text {a }}$

A, Expression of KAI1 by considering clinical stage (I-IV) of pancreatic cancer as pathological factor

\begin{tabular}{lcccc}
\hline Clinical stages & No. & Positive expression, no. & Positive expression rate, $\%$ & P-value \\
\hline I, II & 23 & 11 & 47.82 & $<0.05$ \\
III, IV & 27 & 22 & 96.30 & $<0.05$ \\
\hline
\end{tabular}

B, Expression of KAI1 by considering histological grade of pancreatic cancer as pathological factor

\begin{tabular}{lcccc}
\hline Histological grade & No. & Positive expression, no. & Positive expression rate, \% & P-value \\
\hline High differentiation & 16 & 15 & 93.75 & $<0.05$ \\
Intermediate differentiation & 22 & 15 & 68.19 & $<0.05$ \\
Poor differentiation & 12 & 5 & 41.67 & $<0.05$ \\
\hline
\end{tabular}

C, Expression of KAI1 by considering lymphatic metastasis of pancreas as pathological factor

\begin{tabular}{|c|c|c|c|c|}
\hline Lymphatic metastasis & No. & Positive expression, no. & Positive expression rate, $\%$ & P-value \\
\hline No & 21 & 10 & 47.62 & $<0.05$ \\
\hline Yes & 29 & 28 & 96.55 & $<0.05$ \\
\hline
\end{tabular}

${ }^{a} \mathrm{P}<0.05$ is considered as statistically significant. PTEN, phosphatase and tensin homolog deleted in chromosome 10.

immediately after color was developed in the experimental samples. The primary antibodies used were rabbit anti-PTEN monoclonal antibody (1:100; OriGene Technologies, Inc.,
Rockville, MD, USA) and rabbit anti-KAI-1/CD82 monoclonal antibody (1:100; OriGene Technologies, Inc.). For the secondary antibody, goat anti-rabbit antibody (1:100, BD Biosciences, 
San Jose, CA, USA) was used. The streptavidin-peroxidase kit was purchased from CapitalBio Corporation (Beijing, China).

Histological analysis. The stained slides were analyzed as previously described (7). The presence of brownish yellow granules was considered as a positive expression. A positive cell ratio of $<10 \%$ was defined as negative, while a positive cell ratio of $\geq 10 \%$ was defined as positive. For KAI1 staining, the presence of brownish yellow granules in the cell membrane or cytoplasm was considered as KAI1-positive expression. A positive cell ratio of $<25 \%$ was defined as negative, whereas a positive cell ratio of $\geq 25 \%$ was defined as positive.

Statistical analysis. SPSS 16.0 software (SPSS, Inc., Chicago, IL, USA) was used for the $\chi^{2}$ test for different groups. Data were presented as mean \pm standard deviation. $\mathrm{P}<0.05$ was considered to indicate a statistically significant difference.

\section{Results}

PTEN expression. The positive PTEN expression rate in normal pancreatic tissue was identified as $70.0 \%(7 / 10)$, which was significantly higher compared to that of pancreatic carcinoma $(38.0 \%, 19 / 50)(\mathrm{P}<0.05)$. In addition, a positive PTEN expression rate in pancreatic carcinoma was statistically significant for the different clinical stages, histological grade, and with or without lymphatic metastasis (Table I).

KAIl expression. The positive KAI1 expression rate in normal pancreatic tissue was identified as $30.0 \%$ (3/10), which was significantly lower than that of pancreatic carcinoma $(70.0 \%$, $35 / 50)(\mathrm{P}<0.05)$. A positive KAI1 expression rate in pancreatic carcinoma was statistically significant for the different clinical stages, histological grade, and with or without lymphatic metastasis (Table II).

\section{Discussion}

The incidence of pancreatic cancer has been on the increase. Detection of pancreatic cancer poses a challenge in the absence of effective biomarkers. Additionally, tumor cells are also likely to migrate causing further adverse conditions. Pancreatic cancer is characterized by an increasingly high transfer rate, low excision rate, and low survival rate following surgery (8-10). Tumor suppressor genes are important in the occurrence of pancreatic cancer (11), although the specific underlying mechanism remains to be determined.

The most prominent characteristics of PTEN is its combined structure of phosphotyrosine phosphatase and dual specificity phosphatase (12-14), indicating a dephosphorylation effect on phosphorylated serine or threonine and tyrosine residue, which is directly associated with tumor inhibition. A possible reason is that phosphorylation of tyrosine residues in protein may regulate cell growth and differentiation. PTEN has protein phosphatase activity, which reduces the phosphorylation level of focal adhesion kinase mediated by fibronectin and inhibits its activity, and influences the interaction among cells and between the cells and the extracellular matrix. This results in the successful inhibition of the invasion and metastasis of tumor cells (15-18). By contrast, when the expression of
PTEN is reduced or when PTEN loses its negative regulation on the signal transduction pathway, pancreatic cells may not be regularly regulated, leading to excessive cell proliferation or migration to other areas. Results of the present study showed that a positive PTEN expression rate in normal pancreatic tissue was higher than that in pancreatic carcinoma. As the disease stage increased in later clinical stages (II and IV), the expression of PTEN was downregulated. These findings are consistent with the hypothesis that PTEN is important in the development or transfer of pancreatic cancer (19-21).

The tumor metastasis suppressor gene, KAII is shown to be involved in cancer metastasis by enhancing the infiltration and transfer of cancer cells (22). KAI1 has a stable translational level in pancreatic tissues (23), but has no or minimal activity in healthy pancreatic tissues. The results from the current study show that the positive expression rate of KAI1 protein in normal pancreatic tissues was lower than that in pancreatic carcinoma. Other studies have also shown that the positive expression rate of KAI1 mRNA in normal pancreatic tissues is lower than that in the primary pancreatic carcinoma (24-26). The expression of KAI1 mRNA in advanced pancreatic carcinoma with lymphatic metastasis was significantly higher than that in the early pancreatic carcinoma $(27,28)$. In the present study, we identified that the expression of KAI1 in clinically advanced pancreatic carcinoma was significantly higher than that in the clinically early pancreatic carcinoma. In addition, the expression of KAI1 in pancreatic carcinoma with high cell differentiation was significantly lower than that in pancreatic carcinoma with poor differentiation. Additionally, the expression of KAI1 in pancreatic carcinoma with lymphatic metastasis was higher than that in pancreatic carcinoma without lymphatic metastasis. The result was consistent with previous studies $(27,28)$ and emphasizes that KAI1 is closely associated with the occurrence, development, and transfer of pancreatic cancer.

In conclusion, clinical stages, histological grade, as well as presence or absence of lymphatic metastasis affect the positive expression of PTEN and KAII in pancreatic carcinoma. The two genes are closely associated with lymphatic metastasis and the degree of tumor malignancy.

\section{References}

1. Li Destri G, Giarrizzo A,Bellavia N, Milazzotto R, Frattalone ME, Scilletta B and Di Cataldo A: Synchronous double cancers of the colon and the pancreas: a case report. Eur Rev Med Pharmacol Sci 18 (Suppl 2): 28-31, 2014.

2. Li J, Yen C, Liaw D, Podsypanina K, Bose S, Wang SI, Puc J, Miliaresis C, Rodgers L, McCombie R, et al: PTEN, a putative protein tyrosine phosphatase gene mutated in human brain, breast, and prostate cancer. Science 275: 1943-1947, 1997.

3. Costa HA, Leitner MG, Sos ML, Mavrantoni A, Rychkova A, Johnson JR, Newton BW, Yee MC, De La Vega FM, Ford JM, Krogan NJ, Shokat KM, Oliver D, Halaszovich CR and Bustamante CD: Discovery and functional characterization of a neomorphic PTEN mutation. Proc Natl Acad Sci USA 112: 13976-13981, 2015.

4. Maccioni F, Martinelli M, Al Ansari N, Kagarmanova A, De Marco V, Zippi M and Marini M: Magnetic resonance cholangiography: past, present and future: a review. Eur Rev Med Pharmacol Sci 14: 721-725, 2010.

5. Squadroni M and Fazio N: Chemotherapy in pancreatic adenocarcinoma. Eur Rev Med Pharmacol Sci 14: 386-394, 2010.

6. Hermanek P and Sobin LH (eds). International Union Against Cancer (UICC): TNM Classification of Malignant Tumours. 4th edition. Springer, New York, NY, p71273, 1992. 
7. Depowski PL, Rosenthal SI and Ross JS: Loss of expression of the PTEN gene protein product is associated with poor outcome in breast cancer. Mod Pathol 14: 672-676, 2001.

8. Jiang J, Li Z, Yu C, Chen M, Tian S and Sun C: MiR-1181 inhibits stem cell-like phenotypes and suppresses SOX2 and STAT3 in human pancreatic cancer. Cancer Lett 356 (2 Pt B): 962-970, 2015.

9. Morran DC, Wu J, Jamieson NB, Mrowinska A, Kalna G, Karim SA, Au AY, Scarlett CJ, Chang DK, Pajak MZ, et al; Australian Pancreatic Cancer Genome Initiative (APGI) Targeting mTOR dependency in pancreatic cancer. Gut 63: 1481-1489, 2014.

10. Humphris JL, Johns AL, Simpson SH, Cowley MJ, Pajic M, Chang DK, Nagrial AM, Chin VT, Chantrill LA, Pinese M, et al; Australian Pancreatic Cancer Genome Initiative: Clinical and pathologic features of familial pancreatic cancer. Cancer 120 : 3669-3675, 2014

11. Vazquez F, Ramaswamy S, Nakamura N and Sellers WR Phosphorylation of the PTEN tail regulates protein stability and function. Mol Cell Biol 20: 5010-5018, 2000.

12. Yamaguchi K, Okusaka T, Shimizu K, Furuse J, Ito Y, Hanada K and Shimosegawa T; Committee for revision of clinical guidelines for pancreatic cancer of Japan Pancreas Society: EBM-based Clinical Guidelines for Pancreatic Cancer (2013) issued by the Japan Pancreas Society: A synopsis. Jpn J Clin Oncol 44: 883-888, 2014.

13. Zhan HX, Xu JW, Wu D, Zhang TP and Hu SY: Pancreatic cancer stem cells: new insight into a stubborn disease. Cancer Lett 357: 429-437, 2015

14. Limani P, Samaras P, Lesurtel M, Graf R, DeOliveira ML, Petrowsky $\mathrm{H}$ and Clavien PA: Pancreatic cancer - a curable disease. Praxis (Bern 1994) 104: 453-460, 2015.

15. Grant RC, Selander I, Connor AA, Selvarajah S, Borgida A, Briollais L, Petersen GM, Lerner-Ellis J, Holter S and Gallinger S: Prevalence of germline mutations in cancer predisposition genes in patients with pancreatic cancer. Gastroenterology 148: 556-564, 2015.

16. Huang M, Tang SN, Upadhyay G, Marsh JL, Jackman CP Srivastava RK and Shankar S: Rottlerin suppresses growth of human pancreatic tumors in nude mice, and pancreatic cancer cells isolated from $\operatorname{Kras}(\mathrm{G} 12 \mathrm{D})$ mice. Cancer Lett 353: 32-40, 2014.

17. Stewart DJ, Nunez MI, Jelinek J, Hong D, Gupta S, Aldaz M, Issa JP, Kurzrock R and Wistuba II: Impact of decitabine on immunohistochemistry expression of the putative tumor suppressor genes FHIT, WWOX, FUS1 and PTEN in clinical tumor samples. Clin Epigenetics 6: 13, 2014.
18. Nakanishi A, Kitagishi Y, Ogura Y and Matsuda S: The tumor suppressor PTEN interacts with p53 in hereditary cancer (Review). Int J Oncol 44: 1813-1819, 2014.

19. Suda T, Oba H, Takei H, Kurosumi M, Hayashi S and Yamaguchi Y: ER-activating ability of breast cancer stromal fibroblasts is regulated independently of alteration of TP53 and PTEN tumor suppressor genes. Biochem Biophys Res Commun 428: 259-263, 2012

20. Kim SJ, Jung HJ and Lim CJ: Reactive oxygen species-dependent down-regulation of tumor suppressor genes PTEN, USP28, DRAM, TIGAR, and CYLD under oxidative stress. Biochem Genet 51: 901-915, 2013.

21. Lang Y, Xu S, Ma J, Wu J, Jin S, Cao S and Yu Y: MicroRNA-429 induces tumorigenesis of human non-small cell lung cancer cells and targets multiple tumor suppressor genes. Biochem Biophys Res Commun 450: 154-159, 2014.

22. Yang H, Chen H, Qiu Z, et al: Preliminary screening of drug resistance-related genes downstream of STAT3 in human pancreatic cancer cell. Chin J Gen Surg 20: 925-930, 2011.

23. Gautam A, Li ZR and Bepler G: RRM1-induced metastasis suppression through PTEN-regulated pathways. Oncogene 22: 2135-2142, 2003.

24. Hayashi Y, Kajikawa M, Matsumoto T and Okada N: Mechanism by which a LINE protein recognizes its 3 ' tail RNA. Nucleic Acids Res 42: 10605-10617, 2014.

25. Camenares D, Dulebohn DP, Svetlanov A and Karzai AW: Active and accurate trans-translation requires distinct determinants in the C-terminal tail of SmpB protein and the mRNA-like domain of transfer messenger RNA (tmRNA). J Biol Chem 288: 30527-30542, 2013.

26. Vallazza B, Petri S, Poleganov MA, Eberle F, Kuhn AN and Sahin U: Recombinant messenger RNA technology and its application in cancer immunotherapy, transcript replacement therapies, pluripotent stem cell induction, and beyond. Wiley Interdiscip Rev RNA 6: 471-499, 2015 (In Chinese).

27. Yi X, Jiang T, Zhai H, et al: Experimental study of lentiviral vector intermediate RNAi target on inhibiting the expression of pancreatic cancer cell survivin and its effect in inducing cell apoptosis. Chin J Gen Surg 19: 227-233, 2010 (In Chinese).

28. Xiang $\mathrm{C}$, Zheng Y and Shi Z: The influence of the expression change of microRNA-10b on biological behavior of pancreatic cancer cell. Chin J Gen Surg 21: 1091-1092, 2012. 